\title{
Three Questions: The Journey of One Black Mathematician
}

\section{Edray Herber Goins}

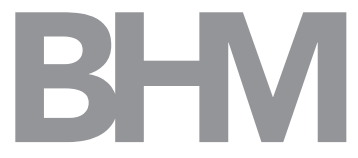

AMC's The Walking Dead features a leader of a group who asks three questions whenever he meets strangers who might possibly join his group. Well, I am the president of the National Association of Mathematicians (NAM), a professional organization that seeks to increase the public awareness of issues of importance to underrepresented minorities in the mathematical sciences, and I would like to modify these questions and ask you the following:

\section{How many African American mathematicians have you graduated?}

How many African American mathematicians have you hired?

Why?

Permit me to take you on a journey of personal growth as I have asked these questions of myself while navigating the mathematical professoriate.

\section{My Undergraduate Days in Pasadena}

She's the terror of Colorado Boulevard / It's The Little Old Lady from Pasadena!

- "The Little Old Lady from Pasadena," The Beach Boys

When I was an undergraduate at the California Institute of Technology, I spent a lot of time wondering about those who looked like me-about African Americans in mathematics, to be precise. I graduated from a predominantly African American high school in Los Angeles in 1990. Yet fifteen miles away in Pasadena there were only 14 Black students in Caltech's freshman class of nearly 180 students. In fact there were fewer than 50 Black students

Edray Goins is professor of mathematics at Purdue University and president of the National Association of Mathematicians. His email address is egoins@purdue.edu.

For permission to reprint this article, please contact: reprint-permission@ams .org.

DOI: http://dx.doi.org/10.1090/noti1637 out of nearly 2,000 undergraduate and graduate students. And there were only 2 Black faculty out of nearly 300 .

I wanted to know: Why were these numbers so low?

As an African American double-majoring in mathematics and physics, I wanted to know whether the numbers were just as low at other universities. In 1992, during my sophomore year, I found out that Stanford University would host the annual National Conference of Black Physics Students (NCBPS). I decided to attend the conference as the sole representative from Caltech, and I was glad that I did. I learned that I wasn't alone as an African American in mathematics and physics. I made friends at that meeting who remain friends to this day. And I met three African Americans at that conference who would become lifelong mentors: Ronald E. Mickens of Clark Atlanta University, Bill Massey of AT\&T Bell Labs, and Sylvester James Gates of the University of Maryland.

But the meeting left me a little confused. There were many capable mathematicians and physicists at this conference-undergraduate students, graduate students, postdoctoral fellows, and faculty. So why were the numbers so small at Caltech?

I asked several faculty about what Caltech had done to recruit faculty over the years. My advisor in physics, Steve Frautschi, told me about the time they tried to hire a young African American physicist from MIT who was a postdoc at Caltech. Unfortunately things didn't work out for several reasons, although he was a pretty successful physicist at the University of Maryland. Frautschi thought it would be great if I met the guy one day. His name was Sylvester James Gates.

So the same person who founded the National Conference of Black Physics Students was almost a Caltech professor? Now I really wanted to learn more. 

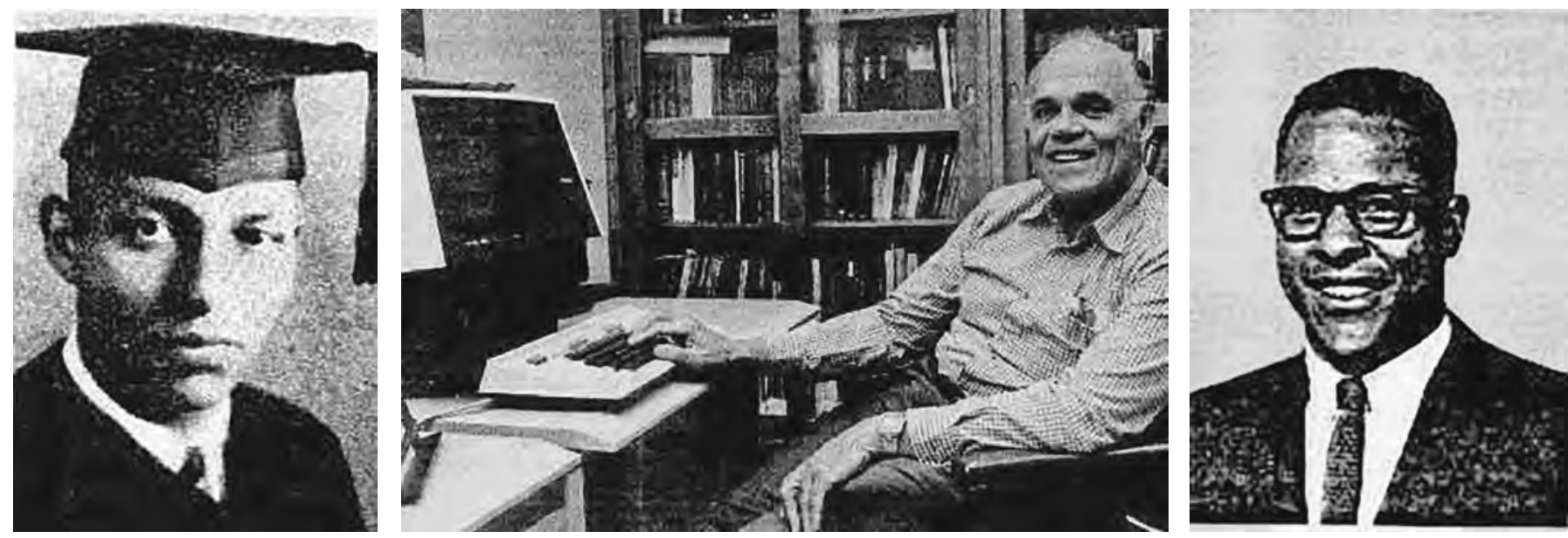

Figure 1. Grant Venerable (BS 1932) was the first African American undergraduate at Caltech. James Lu Valle (PhD 1940) was the first African American graduate student. Charles McGruder (BS 1965) was the second African American undergraduate.

\section{My Brief Stint as a Historian}

The great force of history comes from the fact that we carry it within us, are unconsciously controlled by it in many ways, and history is literally present in all that we do. -James Baldwin

I decided to spend my senior year at Caltech studying the history of African Americans at Caltech. I wanted to know about the first African American undergraduate and graduate students. I wanted to learn more about their experiences, and whether the numbers were always so small.

I had some rather surprising revelations (see Figure 1).

- The first African American undergraduate at Caltech was Grant D. Venerable; he graduated in 1932 with a Bachelor of Science in Civil Engineering.

- The first African American graduate student at Caltech was James Lu Valle; he graduated in 1940 with a Doctorate in Chemistry. In fact, Lu Valle won a bronze medal in the 1936 Olympics in Berlin-yes, the same Olympics where that other African American, Jesse Owens, won a gold medal. The Graduate Student Union at UCLA is named after him, and Morehouse College recently established a fellowship in his honor using funds from Jim Simons.

- The second African American undergraduate at Caltech was Charles Hosewell McGruder; he graduated in 1965 with a Bachelor of Science in Astronomy. There were no other Black undergraduates after Venerable graduated in 1932 until McGruder enrolled in 1961. As fate would have it, I met McGruder at the National Conference of Black Physics Students in 1998, while I was a graduate student.

I also learned that the number of African American students was not always so small. Longtime Caltech employee Lee Browne spent years recruiting students from Los Angeles to attend Caltech. When affirmative action began in earnest in the early 1970s, Browne successfully recruited dozens of African Americans. In fact, the largest

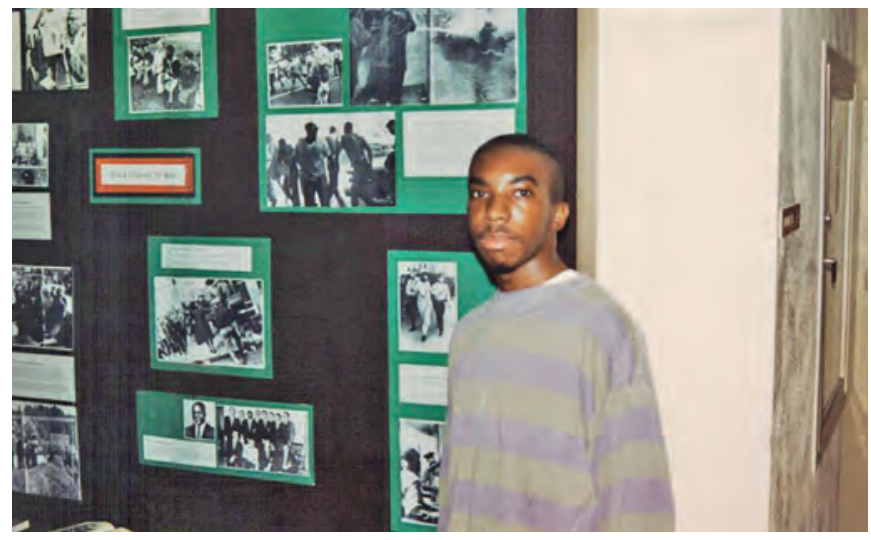

Figure 2. Edray Goins and his Black History Month display at Caltech in 1994.

population of Black students was during the mid 1970s! One of those undergraduates was Robert Thornton, who was my mentor through my scholarship with the American Physical Society (APS). Another was Loretta Carroll, a woman I had known while growing up in Los Angeles. Sadly, I didn't know until I conducted this research that either was a Caltech graduate. In Figure 2 you can see a picture of me next to a prominent display of some of these findings in the Department of Humanities and Social Sciences at Caltech.

With this knowledge, I finally felt connected to a larger community. The numbers of students and faculty were small at Caltech, but there were many others out there with whom I had a historical connection.

\section{Time on the Farm}

We hailin from East Oakland, California and, um Sometimes it gets a little hectic out there But right now, yo, we gonna up you on how we just chill. _-"93 Til Infinity," Souls of Mischief 


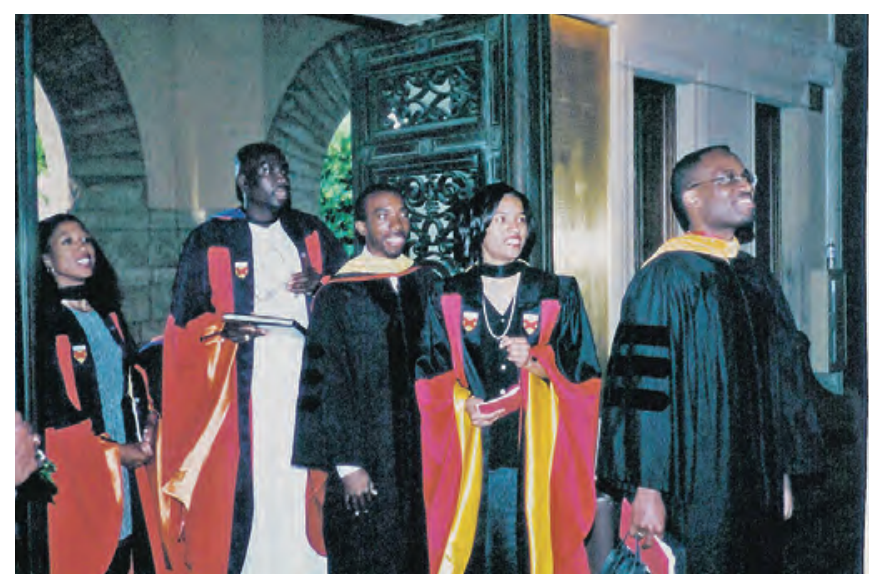

Figure 3. Valerie Nelson, Acha Leke, Edray Goins, Angela Cole, and Duru Ahanotu at Black Graduation at Stanford University in 1999.

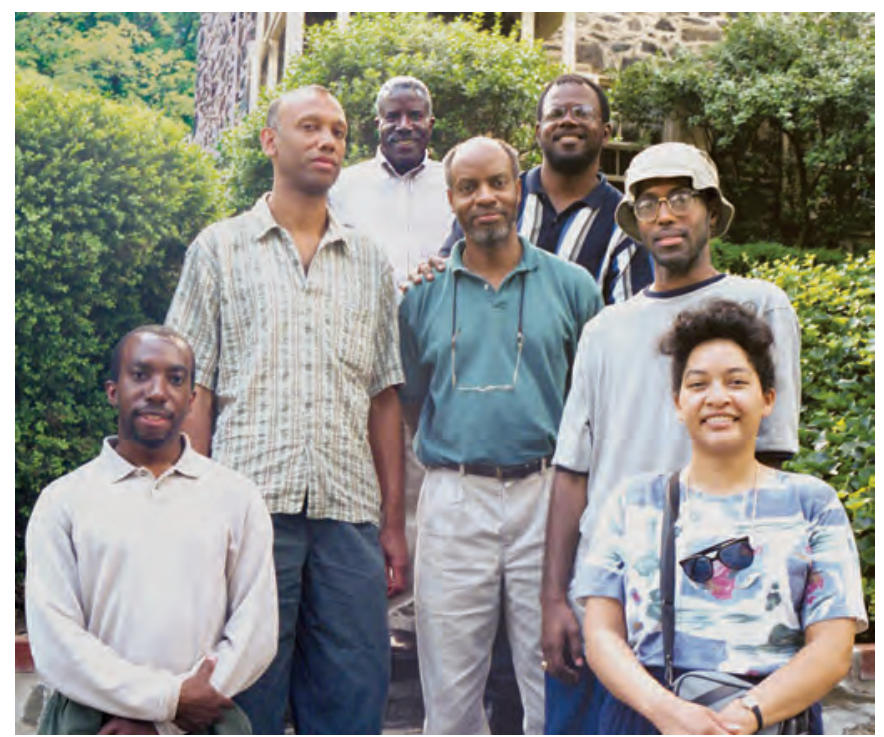

Figure 4. Edray Goins, Carl Graham, Earl Barnes, Mel Currie, Bill Massey, Ahmad Ridley, and Kathy Lewis at CAARMS in 2000 outside the home of Mel Currie.

The 1992 NCBPS meeting at Stanford convinced me that Stanford was where I should pursue my graduate studies. I was a doctoral student in the mathematics department, although I spent a lot of time in the physics department as well. Not surprisingly, the numbers of African American students and faculty at Stanford were very small. I was the only Black student in the mathematics department, and there were no Black professors.

I received a pleasant surprise in my second year at Stanford. The December 1995 issue of the Notices featured a conference for African American mathematicians that had just taken place in Berkeley a few months before. I had mixed feelings: There was a conference for African American Researchers in the Mathematical Sciences (CAARMS)?! How come I didn't know about it until after?!

In the midst of this confusion, I received a phone call one evening. "I'd like to introduce myself," the voice said,
"I am Bill Massey. I started CAARMS." Yes, this was the same person I had met some four years earlier at the NCBPS meeting! "You might be curious to know that I got my doctorate in mathematics from Stanford as well." Massey went on to say there was one other African American to get a doctorate in mathematics from Stanford, so as far as I know there are just three of us now. I may have been the only African American student in mathematics at the time, but I would not be the first African American to graduate from Stanford with a doctorate in mathematics. As proof that I did finish with this degree, Figure 3 shows me and some friends as we marched through Stanford's Black Graduation ceremony.

Once again, I realized that I was part of a larger community than what I was seeing in graduate school. Eventually I would attend many CAARMS conferences and make many more lifelong friends. Figure 4 shows several of us at a later CAARMS in 2000 outside the home of Mel Currie.

\section{Indiana Wants Me}

I'm goin' back to Indiana / Back to where my baby's from I'm goin' back to Indiana / Indiana here I come.

_-"Goin' Back to Indiana," The Jackson 5

By the time I accepted my first tenure-track position at Purdue University, I had nearly resigned myself to the idea that I would just be one of a handful of African Americans in my mathematics department. Still, part of me realized I had to do something to change this.

So I went out to recruit my own African American graduate students. My first graduate student was Kevin Muriithi Mugo, who graduated from Purdue in 2014 (see Figure 5). We met while working together during an NSF-funded REU at Miami University called the Summer Undergraduate Mathematical Sciences Research Institute. I was so impressed by the success Miami University had in recruiting women and underrepresented minorities for their REU that recently I started my own REU titled the Purdue Research in Mathematics Experience (PRiME).

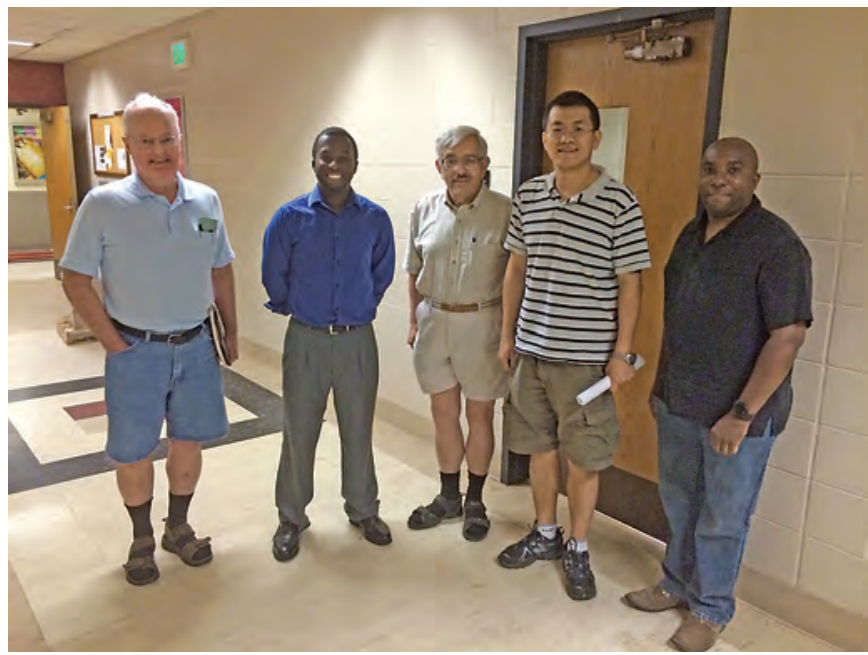

Figure 5. Bill Heinzer, Kevin Muriithi Mugo, Sam Wagstaff, Tong Liu, and Edray Goins after Kevin's thesis defense in summer 2014. 


\section{I'm still looking for answers.}

But I began to wonder much as I had done while an undergraduate: What about the history of African Americans at Purdue? I wanted to know about the first African American graduate students in the mathematics department.

As I tried to ask around Purdue, I realized no one kept records of every African American to come through the math department. Fortunately, one of the first graduates is my mentor as president of NAM, and he had been collecting this information on his own for years! We both discovered that there have been seven African Americans to graduate with a doctorate in mathematics from Purdue:

- Melvin L. Heard, who is now associate professor of mathematics and assistant dean in the College of Liberal Arts at the University of Illinois at Chicago (UIC), finished in 1967 under Robert Arnold Gambill and Merritt S. Webster.

- Benjamin Joseph Martin, who is now head pastor at St. Rest Baptist Church, finished in 1969 under Thomas Wilson Mullikin.

- Johnny L. Houston, who is now emeritus professor of mathematics at Elizabeth City State University (ECSU), finished in 1974 under Eugene V. Schenkman.

- Kathy Marie Lewis, who is now associate professor of mathematics at Morehead State University, finished in 1999 under Carl Cowen.

- Sean Colbert-Kelley, who is now a scientist at the National Institute of Standards and Technology (NIST), finished in 2012 under Daniel Phillips.

- Kevin Muriithi Mugo, finished in 2014 under me.

- Reginald L. McGee, who is now a postdoctoral fellow at the Mathematical Biosciences Institute (MBI), finished in 2015 under Gregery T. Buzzard.

\section{Semper Adquilirens}

Now that I am a full professor at Purdue University, I spend a lot of time pondering the three questions that began this article. How many African American mathematicians have you graduated? My department has graduated seven with doctorates in mathematics, while I have graduated just one. How many African American mathematicians have you hired? Sadly none have been hired as tenure-track during my years at Purdue, although we did hire one as a postdoctoral fellow for three years. Why? I don't know exactly. I have tried to recruit many, many African American students and faculty to Purdue in the thirteen years I've been on the faculty. I'm still looking for answers.

I'm still amazed that, after all of these years, I look to Jim Gates, Bill Massey, and Ronald E. Mickens for advice and inspiration. As president of NAM, I was honored to have Jim Gates serve on our annual NAM Panel Discussion at the 2017 Joint Mathematics Meetings in Atlanta (see Figure 6). As a director of an NSF-funded REU, I was thrilled to have my own undergraduates meet Bill Massey at the 23rd annual CAARMS at the University of Michigan in 2017. And as a lover of mathematics, I am looking forward to watching Ronald Mickens speak at the 2018 Joint Mathematics Meetings in San Diego as NAM's Claytor-Woodard Lecturer.

And yes, I'm still asking them the Three Questions.

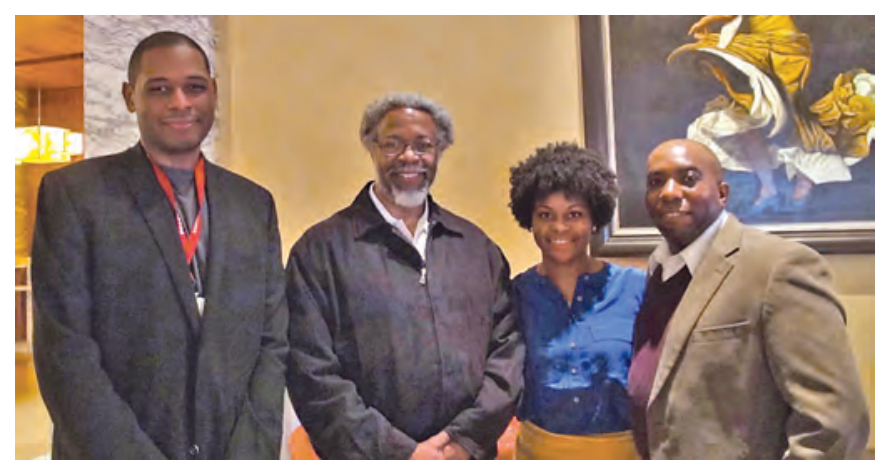

Figure 6. Cory Colbert, Jim Gates, Ebony Harvey, and Edray Goins at the 2015 Joint Mathematics Meetings in San Antonio, Texas.

\section{Photo Credits}

Figure 1, photo of Grant Venerable from the California Institute of Technology Big T, 1932.

Figure 1, photo of James Lu Valle from Stanford University, Campus Report, January 8, 1984.

Figure 1, photo of Charles McGruder from the California Institute of Technology Big T, 1965.

Figures 2-6, and the author photo from the personal collection of Edray Goins.

\section{ABOUT THE AUTHOR}

Edray Goins has been working on properties of Selmer groups for elliptic curves using class groups of number fields, as well as properties of Dessins d'Enfants. He runs an REU that focuses on understanding properties of Belyi maps, and he maintains his own blog about Dessins d'Enfants.

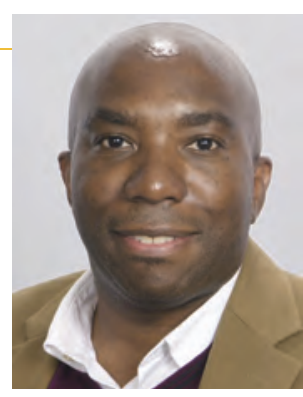

Edray Goins 